OPEN ACCESS

Edited by:

Nuno Sousa,

University of Minho, Portugal

Reviewed by:

Sucharita Sen Somkuwar, Scripps Research Institute, USA Charles L. Pickens,

Kansas State University, USA

*Correspondence:

Selena Bartlett

selena.bartlett@qut.edu.au

Received: 04 October 2016 Accepted: 08 February 2017 Published: 22 February 2017

Citation:

Holgate JY, Shariff M, Mu EWH and Bartlett S (2017) A Rat Drinking in the Dark Model for Studying Ethanol and

Sucrose Consumption.

Front. Behav. Neurosci. 11:29.

doi: 10.3389/fnbeh.2017.00029

\section{A Rat Drinking in the Dark Model for Studying Ethanol and Sucrose Consumption}

\author{
Joan Y. Holgate, Masroor Shariff, Erica W. H. Mu and Selena Bartlett* \\ Institute of Health and Medical Innovation, Translational Research Institute, Queensland University of Technology \\ Woolloongabba, QLD, Australia
}

Background: The intermittent access 2-bottle choice (IA2BC) and drinking in the dark (DID) models were developed for studying rodent binge-like consumption. Traditionally, IA2BC was used with rats and DID with mice. Recently, IA2BC was adapted to study mouse ethanol consumption. However, it is unknown whether DID is suitable for rats or if one rat model is more advantageous than another for studying binge-like consumption.

Methods: Male Wistar rats consumed $20 \%$ ethanol or $5 \%$ sucrose using IA2BC or DID for 12 weeks. IA2BC drinking sessions occurred on alternate days (Mondays-Fridays) and lasted 24 h, whereas DID sessions ran 4 h/day, 5 days/week (Monday-Friday). Average consumption/session, week and hour was measured. To explore DID model suitability for screening novel compounds for controlling ethanol and sucrose intake, varenicline $(2 \mathrm{mg} / \mathrm{kg}$ ) or vehicle was administered to DID rats.

Results: IA2BC rats consume more ethanol/session and similar amounts of ethanol/week than DID rats. While, IA2BC rats consume more sucrose/session and week than DID rats. Although IA2BC rats had more ethanol and sucrose access time, DID rats had greater ethanol and sucrose intake/hour. Varenicline significantly reduced ethanol and sucrose consumption in DID rats, consistent with previously published IA2BC studies.

Conclusions: Despite the shorter access time, the rat DID model induced higher initial intake and greater consumption/hour for both ethanol and sucrose. The shorter duration of DID sessions did not prevent detection of varenicline-induced reductions in ethanol or sucrose consumption, suggesting the DID model may be suitable for studying binge-like ethanol and sucrose consumption.

Keywords: intermittent access 2-bottle choice, drinking in the dark, ethanol, sucrose, varenicline, rat, consumption model
Abbreviations: ADE, alcohol deprivation effect; AUD, alcohol use disorder; BEC, blood ethanol concentration; CDC, Center for Disease Control and Prevention; DID, drinking in the dark; FDA, Federal Drug Administration; IA2BC, intermittent access 2-bottle choice; NIAAA, National Institute on Alcohol Abuse and Alcoholism; NIH, National Institutes of Health; s.c., subcutaneous; WHO, World Health Organization. 


\section{INTRODUCTION}

Harmful consumption of substances, like alcohol and sugar, remain a world-wide health problem. In 2012, 3.3 million deaths were attributed to alcohol consumption and in 2010, 3.4 million deaths to being overweight or obese, with excessive sugar consumption identified as a leading cause of body weight gain (WHO, 2014). With few effective interventions and treatments available, there remains a critical need for the development of new medications and management strategies for reducing alcohol and sugar intake. Rodent consumption models are valuable tools for examining the mechanisms underlying harmful consumption behaviors and developing new therapies. Both rodent species offer advantages and disadvantages for modeling consumption and sometimes the use of a rat model is preferable to a mouse model. For example, rats are generally larger than mice and consequentially have larger brains, allowing the study of smaller brain regions and more accurate placement of cannula, viruses and other probes. Rats also have a slower metabolic rate which expands the timeframe available to measure the effects of potential interventions (like exercise and pharmacotherapeutics) on consumption and reward seeking behaviors. Studies examining the alcohol deprivation effect $(\mathrm{ADE})$ in rats generally produce more consistent results as the ADE last for up to 4 days following the reintroduction of ethanol compared to 1 day in mice (Vengeliene et al., 2014). Additionally, mouse ethanol consumption behaviors differ from rat behaviors. Specifically, mice consuming ethanol using the drinking in the dark model (DID) model, compared to rats using the intermittent access 2-bottle choice (IA2BC) model, display greater insensitive to quinine adulteration of ethanol (a test designed to measure ethanol dependence) making it difficult to dissect the natural compulsive behaviors of the mouse from compulsive behaviors associated with ethanol exposure (Hopf and Lesscher, 2014). However, transgenic mice are more readily available than transgenic rats for isolating genes and signaling pathways involved in modulating consumption behaviors. Hence, it is essential for the researcher to have a diverse and adaptable range of tools and models available for studying all aspects of consumption and related behaviors in both species.

The recent development of two new preclinical rodent models of consumption (DID and IA2BC) has improved our ability to screen and identify novel pharmacotherapeutic targets for the management of consumption behaviors. These models were originally designed to mimic clinically relevant aspects of human addiction defined in the Diagnostic and Statistical Manual (American Psychiatric Association, 2013). Generally, these models are considered to model binge-like consumption as ethanol consumption was demonstrated to be greatest in the period immediately following the start of the drinking sessions (Rhodes et al., 2005). Typically, to more closely model humans, the rodent commences ethanol consumption using these models during adolescence. Many alcoholics report their first ethanol experiences in their teens, a period where the perception of negative properties of alcohol is reduced, leading to a greater propensity for binge consumption and increased risk for developing alcohol use disorders (AUDs) later in life (Clapper and Lipsitt, 1992; Bonomo et al., 2004; Wells et al., 2004). Additionally, preclinical research indicates that exposure to ethanol commencing in adolescence keeps the brain in an adolescent-like state in adulthood (Nielsen et al., 2012b), providing insight into why commencing ethanol consumption in adolescents results in greater ethanol consumption compared to those commencing ethanol consumption as adults (Vetter et al., 2007). Sucrose, on the other hand, was traditionally used in these models as a natural reward control, to demonstrate the effects of the novel compound were specific to ethanol consumption and not consumption in general. However, with the recent accumulation of evidence supporting the addictive properties of sugar and its ability to modulate the same reward pathway that drugs of abuse act upon (for reviews, see Avena et al., 2008; Benton, 2010), the IA2BC and DID models are increasingly being used to study sucrose consumption (for examples, see Galic and Persinger, 2002; Steensland et al., 2010; Mangabeira et al., 2015; Shariff et al., 2016).

Two-bottle choice (2BC) models, like the IA2BC and DID models are often chosen for studying consumption behaviors as they are technically simple and accessible to most researchers, and generally facilitate levels of consumption that are considered clinically relevant to the targeted human condition (for reviews, see McBride and Li, 1998; Carnicella et al., 2014; Griffin, 2014). They also provide the rodent the opportunity to choose how much ethanol or sucrose they wish to consume-a desirable model quality since the loss of control over the ability to choose not to consume the desired substance, despite being aware of the negative consequences, is a defining criterion for addiction (American Psychiatric Association, 2013). Many 2BC models also involve intermittent periods of access to ethanol. This type of consumption/withdrawal cycle can produce escalating binge-like patterns of consumption, intoxication and withdrawal symptoms during periods of abstinence, which are also indicators of dependence (American Psychiatric Association, 2013; Carnicella et al., 2014).

Currently, the IA2BC and DID models are the only two voluntary consumption models available which can produce moderate to high levels of ethanol consumption in rodents without using sucrose-fading to induce ethanol consumption and are generally considered models of binge-like consumption. Wise (1973) first developed the IA2BC model. Simms et al. (2008) extended this work, showing the IA2BC model could be used to produce rats which consumed $20 \%$ ethanol at high levels $(\sim 5-6 \mathrm{~g} / \mathrm{kg} / 24 \mathrm{~h}$ ), with approximately $30 \%$ of the rats achieving BECs around $90-100 \mathrm{mg} / \mathrm{dL}$ - meeting one of the National Institute on Alcohol Abuse and Alcoholism (NIAAA) criteria for binge drinking in humans (National Institute on Alcohol Abuse and Alcoholism (US) (2004)). Additionally, comparison of the IA2BC model with the traditional (non-bingelike) $10 \%$ continuous access 2 BC model demonstrated a $40 \%$ increase in total ethanol consumption and improved sensitivity for detecting changes in ethanol consumption following administration of two different Federal Drug Administration (FDA) approved AUD medications, highlighting the importance of providing intermittent over continuous access to ethanol 
(Simms et al., 2008). The IA2BC model involves providing rats with access to one bottle of water and one of ethanol for $24 \mathrm{~h}$ on alternative days (Monday, Wednesday and Friday). Around the same time, work by Rhodes et al. (2005) demonstrated that the DID model could produce consumption of $20 \%$ ethanol at high levels ( $\sim 2-3 \mathrm{~g} / \mathrm{kg} / 2 \mathrm{~h}$ and $\sim 7 \mathrm{~g} / \mathrm{kg} / 4 \mathrm{~h}$ ) and achieved blood ethanol concentrations (BECs) above $100 \mathrm{mg} / \mathrm{dL}$ in mice (Rhodes et al., 2005). The DID model provides mice with access to one bottle of water and one of ethanol for $2-4 \mathrm{~h}, 3 \mathrm{~h}$ into the dark phase of the light cycle, Monday to Friday.

Since the publication of both these models, the IA2BC model has predominantly been used to study ethanol consumption in rats and the DID for studies in mice, with both models demonstrating translation of discovered novel compounds into human clinical trials (for examples see Lhuintre et al., 1990; Mitchell et al., 2012). While the IA2BC is simple to use and accessible to most researchers, it has fewer consumption/withdrawal cycles per week (3 cycles/week) compared to the DID model (5 cycles/week), thereby offering fewer exposures to and withdrawals from ethanol per week in the same time-frame as the DID model. This becomes particularly important when conducting dose curve studies with novel compounds. Typically, the first day of the week is used to establish stable baseline drinking levels, the second day for the administration of one dose of the compound being examined and the third day to re-establish baseline consumption and eliminate any potential rebound effects. This means that the completion of dose curve studies using the IA2BC model can take over a month to complete as there are only three drinking sessions per week and only one dose can be tested per week. The DID model, on the other hand has five drinking sessions per week, producing more exposures in a shorter time period and potentially allowing two different doses to be tested per week. Using the IA2BC model for a dose curve study can result in significant differences in both the age of the rat and number of ethanol or sucrose exposures at which each dose is administered. While a latin square design is used to compensate for these differences, there is still the potential for increased noise and false negatives. Additionally, the dramatic rise in global rates of obesity and the subsequent burden of care faced by society has led to an increasing need for the development of rodent models for studying harmful sucrose consumption and its effects on the brain. Given the similarities between the effects of sucrose and other addictive substances on the reward pathway (Lemon et al., 2004; Spangler et al., 2004; Lenoir et al., 2007), ethanol consumption models are increasingly being adapted to study sucrose consumption. We recently utilized the IA2BC model in Wistar rats to show long-term binge-like sucrose consumption leads to morphological changes in the nucleus accumbens (Klenowski et al., 2016). We also demonstrated that varenicline, a partial agonist at $\alpha 4 \beta 2$ subunit containing nicotinic acetylcholine receptors, previously shown to reduce nicotine and ethanol consumption (Coe et al., 2005; Steensland et al., 2007), also reduces sucrose consumption (Shariff et al., 2016).

While ethanol and/or sucrose consumption studies have been conducted in mice using both the IA2BC and DID models and rats using the IA2BC model, it is currently unknown whether the DID model can be directly transferred to rats or if there are any benefits of using one model over the other for studying ethanol or sucrose binge-like consumption in rats. Specifically, it is unknown whether one model produces greater binge-like consumption than the other or if one model is more suitable for studying sucrose verses ethanol consumption behaviors. Here, we compare the DID and IA2BC models in Wistar rats consuming ethanol or sucrose. We explore whether the ethanol DID rat model meets the NIAAA binge drinking criteria. Additionally, we examine whether the reduced access time of the DID model impacts the efficacy of varenicline, a compound previously shown to reduce both ethanol and sucrose consumption using the rat IA2BC model (Steensland et al., 2007; Shariff et al., 2016).

\section{MATERIALS AND METHODS}

\section{Drugs}

Five percent $(\mathrm{w} / \mathrm{v})$ sucrose (Sigma, ST. Louis, MO, USA) and $20 \%(\mathrm{v} / \mathrm{v})$ ethanol solutions (Chem-supply, SA, Australia) were prepared in filtered water. Varenicline $(6,7,8,9$-tetrahydro6,10-methano- $6 H$ pyrazino[2,3- $h][3]$ benzazepine tartrate) was purchased from Tocris (Bristol, UK).

\section{Animals and Housing}

Five week old male Wistar rats (193.7 \pm 15.8 g; Animal Resource Centre, Perth, WA, Australia), were individually housed in ventilated Plexiglas cages (Tecniplast, Italy). The rats were acclimatized to the individual housing conditions, handling and reverse-light cycle for 5 days before the start of the experiments. All rats were housed in a climate-controlled 12-h reversed light cycle (lights off 9 am: lights on $9 \mathrm{pm}$ ) room with unlimited access to standard rat chow and water. The experimental procedures followed the ARRIVE guidelines (https://www.nc3rs.org.uk/arrive-guidelines) and were approved by the Queensland University of Technology Animal Ethics Committee and the University of Queensland Animal Ethics Committee, in accordance with the National Institutes of Health (NIH) guidelines for the care and use of laboratory animals.

\section{Intermittent-Access Two-Bottle Choice Model}

The IA2BC drinking procedure was performed as previously described (Steensland et al., 2007; Shariff et al., 2016). All fluids were presented in 300-ml graduated plastic bottles with stainlesssteel drinking spouts inserted through two grommets in the front of the cage immediately following the commencement of the dark phase of the light cycle ( $9 \mathrm{am})$. As previously reported, two bottles were presented simultaneously: one bottle containing water; the second bottle containing 5\% (w/v) sucrose (Nielsen et al., 2008; Simms et al., 2011, 2012; Srinivasan et al., 2012; Klenowski et al., 2016; Patkar et al., 2016; Shariff et al., 2016) or 20\% (v/v) ethanol (Steensland et al., 2007; Nielsen et al., 2008; Simms et al., 2008, 2010, 2012, 2014; Bito-Onon et al., 2011; Mill et al., 2013; Augier et al., 2014; Carnicella et al., 2014; Feduccia et al., 2014). The 
A

IA2BC Experimental Timeline

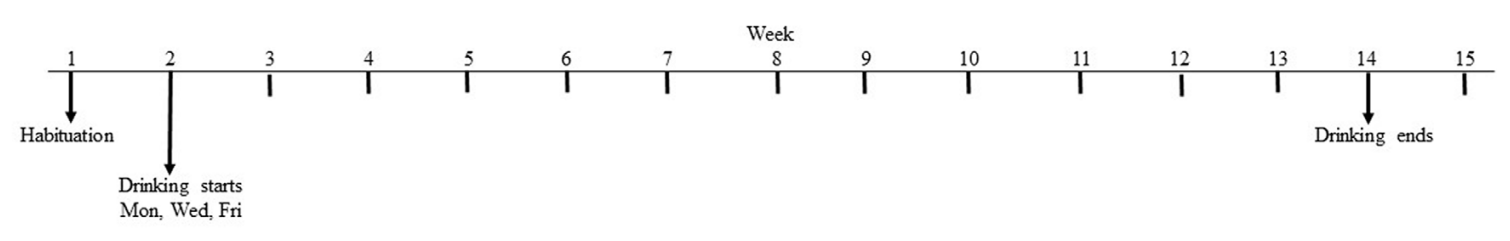

B DID Experimental Timeline

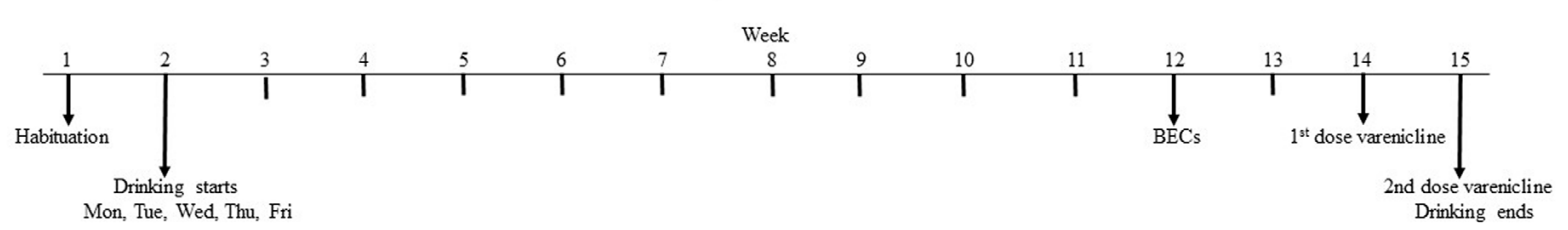

FIGURE 1 | Experimental timeline for the intermittent access 2-bottle choice (IA2BC) and drinking in the dark (DID) models. Five week old male Wistar rats are given 1 week to habituate to the experimental housing conditions before commencing consumption of $20 \%$ ethanol or $5 \%$ sucrose using the IA2BC (A) or DID (B) models. Rats consuming ethanol using the DID model also had blood collected for blood ethanol concentration (BEC) measurement after 10 weeks of drinking sessions. After 12 weeks of ethanol or sucrose consumption, DID rats received 2 once weekly injections of vehicle or $2 \mathrm{mg} / \mathrm{kg}$ varenicline in pseudorandom order, such that each rat served as their own control.

placement of the sucrose/ethanol bottle was alternated with each exposure to control for side preferences. Bottles were weighed $30 \mathrm{~min}, 2 \mathrm{~h}$ and $24 \mathrm{~h}$ after the fluids were presented, with measurements taken to the nearest $0.1 \mathrm{~g}$. The weight of each rat was also measured to calculate the grams of sucrose or ethanol intake per kilogram of body weight. On the Monday after the end of the housing acclimatization period, rats (193.7 $\pm 15.8 \mathrm{~g}$, $n=8$ per group) were given access to one bottle of sucrose or ethanol and one bottle of water. After $24 \mathrm{~h}$, the sucrose/ethanol bottle was replaced with a second water bottle that was available for the next $24 \mathrm{~h}$. This pattern was repeated on Wednesdays and Fridays; all other days the rats had unlimited access to 2 bottles of water for 60 drinking sessions (see Figure 1A). For the sucrose experiments, due to technician error the measurements were not recorded at the $30 \mathrm{~min}$ and $2 \mathrm{~h}$ time points for the first 2 weeks of exposure (sessions 1-6, inclusive) and all measurements ceased after session $35(n=12)$. While measurements were not recorded the rats continued to have access to sucrose during this time. For the ethanol experiments, measurements were collected at all time points from session 1 through $60(n=8)$.

\section{Drinking in the Dark Two-Bottle Choice Model}

The DID 2BC model was originally adapted from Rhodes et al. (2005) and modified to a $4 \mathrm{~h}$ daily access procedure for studying long-term ethanol consumption in mice by Santos et al. (2013). We used the methods described by Santos et al. (2013) in rats. The housing conditions, bottles and fluid concentrations were kept identical to the IA2BC procedure described above. However, the bottles were presented daily (Monday to Friday) for $4 \mathrm{~h}, 3 \mathrm{~h}$ following the commencement of the dark phase of the light cycle $(12 \mathrm{pm})$ and bottle measurements were taken at $30 \mathrm{~min}, 2 \mathrm{~h}$ and $4 \mathrm{~h}$ after the fluids were presented. Drug administration began after the rats ( $n=8$ per group) had been consuming ethanol or sucrose for 10-12 weeks as the effects of ethanol and sucrose on the brain and the efficacy of varenicline are more robust following long term exposure (Klenowski et al., 2016; Patkar et al., 2016; Shariff et al., 2016). As previously described (Steensland et al., 2007; Patkar et al., 2016; Shariff et al., 2016), varenicline (2 $\mathrm{mg} / \mathrm{kg})$ or vehicle $(0.9 \%$ saline) were administered by subcutaneous (s.c.) injection, $30 \mathrm{~min}$ before the drinking session, once per week over 2 weeks at a volume of $1 \mathrm{ml} / \mathrm{kg}$ using a Latin square design, such that each rat received both doses and served as their own control. For both the ethanol $(n=8)$ and sucrose $(n=8)$ experiments, all measurements were collected at all time points from session 1 through 65 but only sessions 1-50 are used to assess baseline consumption due to blood collection in week 10 and drug testing in weeks 12 and 13 (see Figure 1B).

\section{Blood Ethanol Measurements}

The rats were anesthetized with isoflurane and tail blood collected $30 \mathrm{~min}$ after bottle presentation in the 10th week of ethanol consumption. Approximately $100 \mu \mathrm{l}$ of whole blood was collected into tubes containing $10 \mu \mathrm{L}$ of $2.5 \mathrm{M}$ EDTA. The blood was centrifuged at $4^{\circ} \mathrm{C}$ for $20 \mathrm{~min}$ at $1500 \times \mathrm{g}$ and the serum aliquoted and stored at $-80^{\circ} \mathrm{C}$ until assayed. BECs were determined using the nicotinamide adenine dinucleotide (NAD)-alcohol dehydrogenase (ADH) spectrophotometric assay as previously described (Zapata et al., 2006; Santos et al., 2013). All reagents used in this assay were purchased from Sigma-Aldrich (St. Louis, MO, USA). All samples and standards were run in triplicate 
and BECs were calculated using a standard calibration curve.

\section{Statistics}

Statistical analysis was performed using GraphPad Prism software (version 6, USA) and all results are expressed as mean \pm standard error of the mean (SEM). Unpaired T-test with Holm-Sidak method (alpha value adjusted to 0.017 using Sidak correction) was used to compare consumption at each time point and to compare vehicle and varenicline treatments at each time point. Unpaired, two-tailed Student's T-test was used to compare hourly and weekly consumption. Linear Regression and Pearson's $r$ coefficient were performed for the BEC and ethanol consumption of each DID rat. Multiple $t$-tests with Holm-Sidak correction (alpha $=0.010$ ) were used to compare consumption at each time point, per week and per hour for each model and reinforcer.

\section{RESULTS}

\section{Comparing Ethanol Consumption per Drinking Session Using the IA2BC and DID Models}

To determine whether the DID model could be used to induce high ethanol consumption in rats, we compared the average ethanol consumption per drinking session for the first 50 sessions in rats using the DID model with rats using the established IA2BC model (for review of IA2BC model see Carnicella et al., 2014). In this study, the average amount of ethanol consumed in the first $30 \mathrm{~min}$ was greater for DID rats $(0.73 \pm 0.077 \mathrm{~g} / \mathrm{kg} / 30 \mathrm{~min})$ compared to IA2BC rats $(0.81 \pm 0.074 \mathrm{~g} / \mathrm{kg} / 30 \mathrm{~min}$; Figure $2 \mathrm{~A}$, unpaired $T$-test with Holm-Sidak correction, $p=0.0130, n=8)$. The average amount of ethanol consumed after $2 \mathrm{~h}$ ethanol access was similar for IA2BC and DID rats $(1.28 \pm 0.098 \mathrm{~g} / \mathrm{kg} / 2 \mathrm{~h}$ and $1.23 \pm 0.093 \mathrm{~g} / \mathrm{kg} / 2 \mathrm{~h}$, respectively; Figure 2B, T-test with Holm-Sidak correction, $p=0.5087, n=8$ ). However, the average amount of ethanol consume during the entire drinking session was greater for IA2BC rats $(3.34 \pm 0.362 \mathrm{~g} / \mathrm{kg} / 24 \mathrm{~h})$ compared to
DID rats $(1.83 \pm 0.140 \mathrm{~g} / \mathrm{kg} / 4 \mathrm{~h}$; Figure $2 \mathrm{C}$, unpaired $T$-test with Holm-Sidak correction, $p<0.0001, n=8$ ).

\section{DID and IA2BC Rats Consume Similar Amounts of Ethanol per Week}

Although the rats using the IA2BC model consumed more ethanol per session compared to the DID model, each model possessed differences in the amount of time available per session to access ethanol and the number of drinking sessions per week. First, different lengths of time were needed to reach the same number of drinking sessions for each model. For example, the IA2BC rats needed to drink for 10 weeks to complete 30 sessions whereas the DID rats only needed to drink for 6 weeks to complete the same number of drinking sessions. Second, the amount of time the rats were able to access the ethanol per week was different between the models: the IA2BC rats had $3 \times 24 \mathrm{~h}$ sessions $(72 \mathrm{~h})$ per week compared to $5 \times 4 \mathrm{~h}$ sessions $(20 \mathrm{~h})$ per week for the DID rats. To determine how the weekly differences in ethanol access (session time and number) affected the total amount of ethanol the rats received, we compared the average amount of ethanol consumption per week (Figure 3A). We also compared the average amount of ethanol consumed per hour (Figure 3B) for each model. Using unpaired two-tailed Student's $T$-test we found no difference in the amount of ethanol consumed per week (IA2BC: $10.56 \pm 1.163 \mathrm{~g} / \mathrm{kg} /$ week and DID: $8.94 \pm 0.687 \mathrm{~g} / \mathrm{kg} /$ week, $p=0.2626, n=8$ ). However, the amount of ethanol consumed per hour was greater for the DID rats $(0.46 \pm 0.013 \mathrm{~g} / \mathrm{kg} / \mathrm{h})$ compared to IA2BC rats $(0.14 \pm 0.007 \mathrm{~g} / \mathrm{kg} / \mathrm{h}$; unpaired two-tailed Student's T-test, $p<0.0001, n=8)$.

\section{Assessing the DID Model Against NIAAA Binge Drinking Criteria}

In 2004, the NIAAA set out criteria for defining binge drinking in humans. A binge drinking session was defined as a pattern of drinking alcohol that causes a blood alcohol concentration of at least $80 \mathrm{mg} / \mathrm{dL}$, which equates to approximately five or more drinks consumed by an adult male in $2 \mathrm{~h}$ (National Institute on Alcohol Abuse and Alcoholism (US) (2004)). We estimated
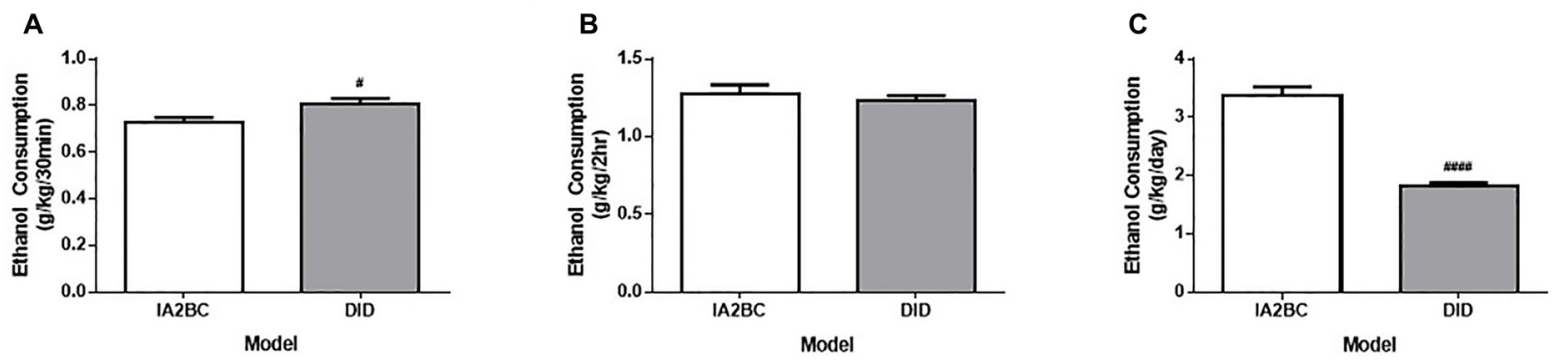

FIGURE 2 | Comparison of ethanol consumption per session using the IA2BC and DID models. (A) Rats using the DID model (gray) consumed more 20\% ethanol than IA2BC rats (white) following 30 min of ethanol access. (B) However, following $2 \mathrm{~h}$ of ethanol access, both the DID and IA2BC rats consumed similar amounts of ethanol. (C) The total amount of ethanol consumed per session was greater for rats using the IA2BC model compared to the DID model. $n=8$. Unpaired

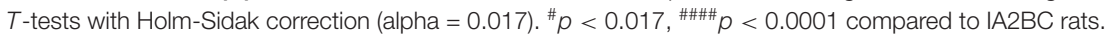



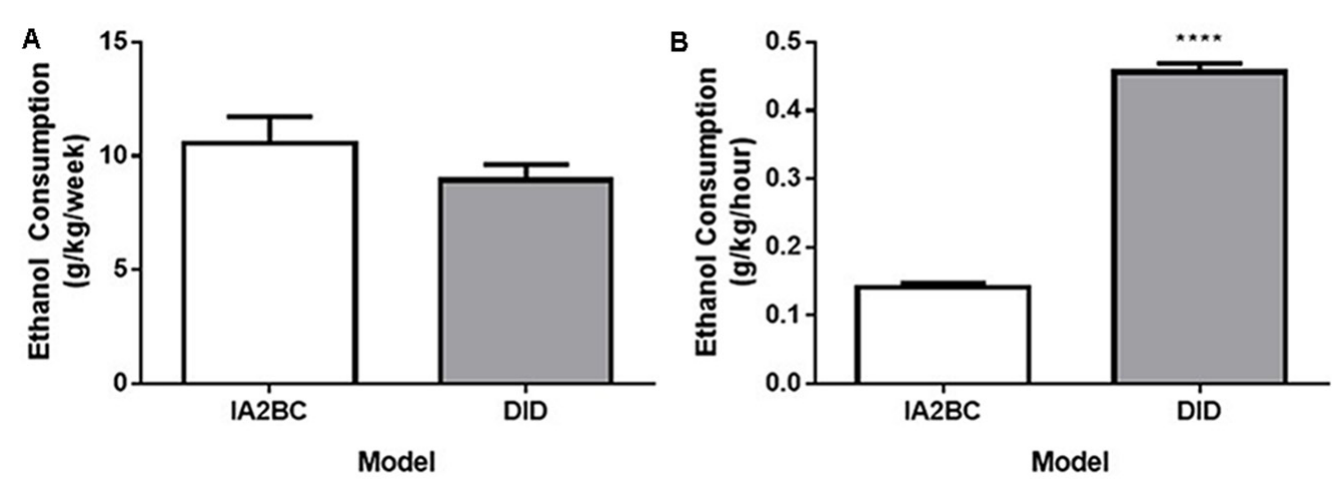

FIGURE 3 | Comparison of weekly and hourly ethanol consumption using the IA2BC and DID models. (A) Rats consuming $20 \%$ ethanol using the DID (gray) and IA2BC (white) model consumed similar amounts of ethanol per week. (B) However, the average amount of ethanol consumed per hour was greater for rats using the DID model compared to the IA2BC model $n=8$ per group. Two tailed unpaired Student's $T$-test. ${ }^{* * * *} p<0.0001$ compared to IA2BC rats.

that an average adult male would need to consume around $0.87 \mathrm{~g} / \mathrm{kg}$ in $2 \mathrm{~h}$ to meet the criteria of binge drinking based on one standard drink containing $14 \mathrm{~g}$ of pure alcohol (CDC, 2016) and $80.7 \mathrm{~kg}$ for the average body weight of an adult in North America (Walpole et al., 2012). However, we could not find similar criteria for binge-like consumption for rodents in the literature and it appears most rodent models of consumption have been designed based on human criteria. As such, we were limited to comparing the rodent consumption from each model with the human binge criteria. Both the IA2BC and DID rats consumed more than $0.87 \mathrm{~g} / \mathrm{kg}$ during the first $2 \mathrm{~h}$ of their ethanol consumption sessions (IA2BC: $1.28 \pm 0.098 \mathrm{~g} / \mathrm{kg} / 2 \mathrm{~h}$ and DID: $1.23 \pm 0.093 \mathrm{~g} / \mathrm{kg} / 2 \mathrm{~h}$ ). Next, we collected blood from the DID rats to determine whether they reached BECs of $80 \mathrm{mg} / \mathrm{dL}$ or greater (BECs for IA2BC rats have been reported previously, see Simms et al., 2008). We measured BECs $30 \mathrm{~min}$ after the commencement of a standard drinking session during the 10th week of ethanol consumption (as previously published Steensland et al., 2007; Simms et al., 2008). Thirty minute BECs were chosen over $2 \mathrm{~h}$ BEC measurements as rodent metabolic rates are different to humans and previous studies indicate peak BECs using the IA2BC model are achieved by this time point in rodents (Simms et al., 2008; Cippitelli et al., 2012; George et al., 2012). We compared 30 min BECs with the amount of ethanol consumed during the $30 \mathrm{~min}$ prior to blood collection (Figure 4). The average BEC was $24.45 \pm 4.826 \mathrm{mg} / \mathrm{dL}$ and BECs ranged from 14.24 to $54.00 \mathrm{mg} / \mathrm{dL}$. Ethanol consumption in the $30 \mathrm{~min}$ prior to blood collection was $1.01 \pm 0.153 \mathrm{~g} / \mathrm{kg} / 30 \mathrm{~min}$, ranging from 0.50 to $1.64 \mathrm{~g} / \mathrm{kg} / 30 \mathrm{~min}$. There was a significant correlation of BECs with ethanol consumption $\left(R^{2}=0.598\right.$, $p<0.05)$. However, none of the DID rats BECs met the NIAAA binge drinking criteria of $80 \mathrm{mg} / \mathrm{dL}$ after $30 \mathrm{~min}$ of ethanol access.

\section{Varenicline Reduces Ethanol Consumption in DID Rats}

Despite the differences in ethanol consumption per session, the DID and IA2BC models resulted in the rats receiving

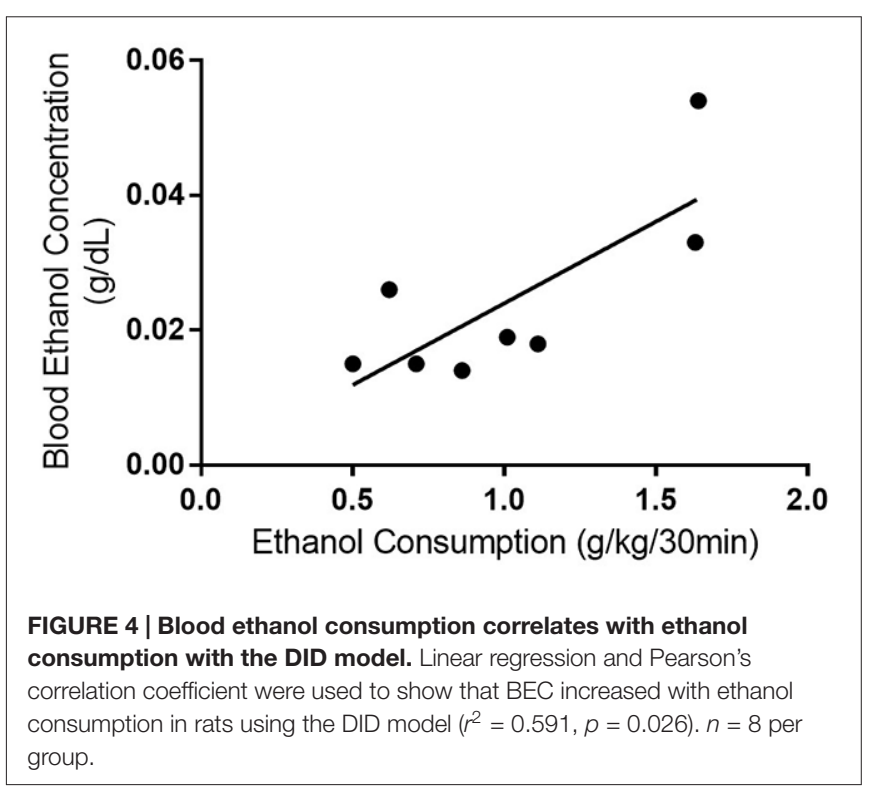

similar amounts of ethanol each week and a higher initial and hourly consumption rate in DID rats. Therefore, to examine whether the differences in consumption produced by each model and the differences in ethanol access times affected model suitability for pre-clinical screening of novel compounds as potential treatments for controlling ethanol consumption, we next assessed whether the DID model could detect reductions in ethanol consumption following treatment with varenicline. Using the IA2BC model in rats, we have previously shown that varenicline $(2 \mathrm{mg} / \mathrm{kg})$ reduces ethanol consumption following $30 \mathrm{~min}$ and $6 \mathrm{~h}$ of ethanol access (Steensland et al., 2007). In this study using DID rats, varenicline also significantly reduced ethanol consumption compared to vehicle at $30 \mathrm{~min}$ (Figure 5A) and $2 \mathrm{~h}$ (Figure 5B) but not $4 \mathrm{~h}$ (Figure 5C) following bottle presentation (Unpaired $T$-test with Holm-Sidak correction, 30 min: $p=0.0003,2$ h: $p<0.0101,4$ h: $p<0.0232$, $n=8)$. 

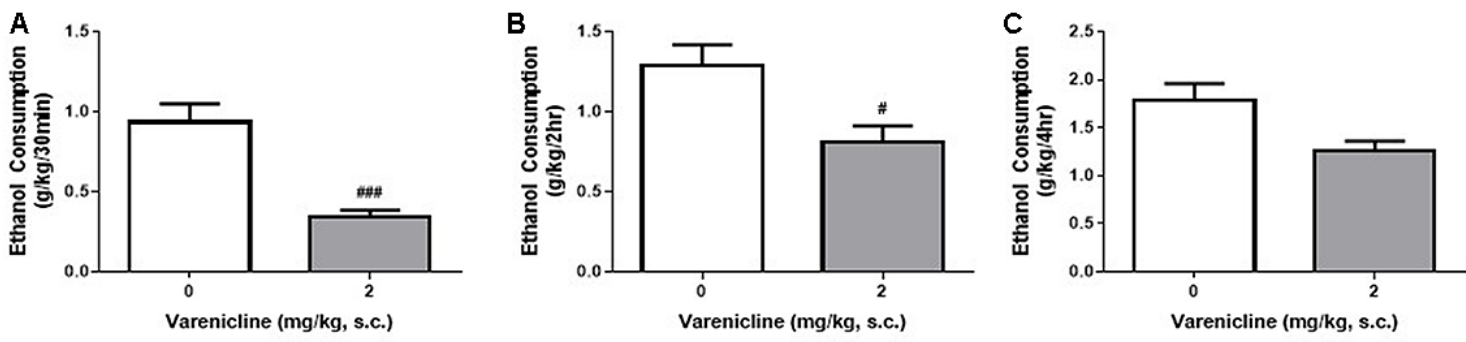

FIGURE 5 | Varenicline reduces ethanol consumption in DID rats. Administration of $2 \mathrm{mg} / \mathrm{kg}$ varenicline (gray) produced a significant reduction in ethanol consumption 30 min (A), 2 h (B) but not 4 h (C) after the commencement of a standard DID drinking session compared to vehicle (white). $n=8$ per group. Unpaired $T$-tests with Holm-Sidak correction (alpha $=0.017)$. ${ }^{\#} p<0.017$, ${ }^{\# \# \# ~} p<0.001$ compared to vehicle.

\section{Daily Sucrose Consumption Using the IA2BC and DID Models}

To determine whether the DID model could also be used to study sucrose binge-like consumption in rats, we compared daily sucrose consumption using the IA2BC and the DID model. As demonstrated by Srisontiyakul et al. (2016), a significantly lower concentration of sucrose is required to produce similar reward seeking behaviors to ethanol, therefore 5\% rather than $20 \%$ sucrose was presented to the rats during drinking sessions. We have recently shown long-term (10 weeks) consumption of 5\% sucrose using the IA2BC model leads to morphological changes in the brain (Klenowski et al., 2016), indicating suitability of this procedure for modeling the effects of long-term binge-like sucrose consumption on the brain. Analysis using the unpaired $T$-test with Holm-Sidak correction revealed that IA2BC rats consumed similar amounts of sucrose than DID rats after $30 \mathrm{~min}$ but less sucrose compared to DID rats after $2 \mathrm{~h}$ of sucrose access (30 min: Figure 6A, $p=0.0171$ and $2 \mathrm{~h}$ : Figure 6B, $p<0.0001)$. However, the IA2BC rats consumed more sucrose per session than DID rats (Figure 6C, $p<0.0001$ ). The average amount of sucrose consumed using the IA2BC model was $1.98 \pm 0.085 \mathrm{~g} / \mathrm{kg} / 30 \mathrm{~min}, 3.58 \pm 0.198 \mathrm{~g} / \mathrm{kg} / 2 \mathrm{~h}$ and $19.85 \pm 0.881 \mathrm{~g} / \mathrm{kg} / 24 \mathrm{~h}$ and for the DID model it was $2.21 \pm 0.138 \mathrm{~g} / \mathrm{kg} / 30 \mathrm{~min}, 4.52 \pm 0.220 \mathrm{~g} / \mathrm{kg} / 2 \mathrm{~h}$ and $8.19 \pm 0.410 \mathrm{~g} / \mathrm{kg} / 4 \mathrm{~h}$.

\section{The IA2BC Model Induces Greater Total Sucrose Intake per Week}

Next, to further examine the sucrose consumption produced by each model, we compared the average amount of sucrose consumed per week (Figure 7A) and the amount of sucrose consumed per hour (Figure 7B). Using the unpaired, two-tailed Student's $T$-test we found rats using the IA2BC model consumed more sucrose per week $(p<0.0001)$ but less sucrose per hour $(p<0.0001)$ compared to DID rats. The IA2BC rats consumed $60.50 \pm 2.731 \mathrm{~g} / \mathrm{kg}$ of sucrose per week and $0.83 \pm 0.022 \mathrm{~g} / \mathrm{kg}$ per hour whereas the DID rats consumed $37.30 \pm 1.727 \mathrm{~g} / \mathrm{kg}$ of sucrose per week and $2.05 \pm 0.045 \mathrm{~g} / \mathrm{kg}$ per hour.

\section{Varenicline also Reduces Sucrose Consumption Using the DID Model}

Given the differences daily, weekly and hourly consumption in the DID and IA2BC rats, we wanted to know whether the reduced access times of the DID model impacted the ability to detect varenicline-induced reductions in sucrose consumption. We have previously shown, using the IA2BC model, that varenicline $(2 \mathrm{mg} / \mathrm{kg}$, s.c.) reduces sucrose consumption following $30 \mathrm{~min}$ but not $2 \mathrm{~h}$ of sucrose access (Shariff et al., 2016). Similar to our previous IA2BC study, varenicline significantly reduced sucrose consumption compared to vehicle after $30 \mathrm{~min}$ (Figure 8A)
A

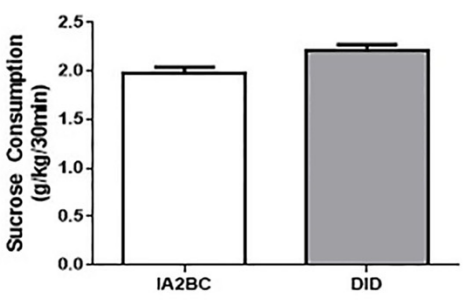

B

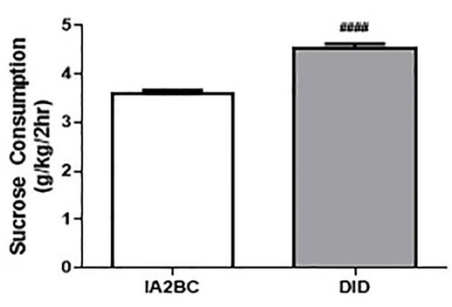

C

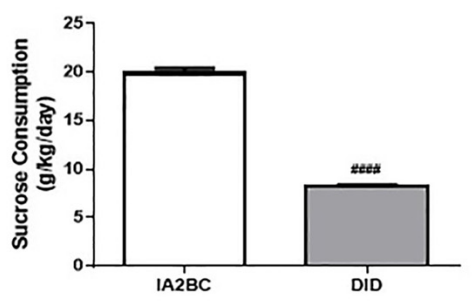

FIGURE 6 | Comparison of sucrose consumption per session using the IA2BC and DID models. Using the DID model (gray), rats consumed similar amounts of $5 \%$ sucrose than rats using the IA2BC model (white) following $30 \mathrm{~min}$ (A) and more sucrose after $2 \mathrm{~h}$ (B) of sucrose access. (C) However, the total amount of sucrose consumed per session was greater for rats using the IA2BC model compared to the DID model $n=8-12$ per group. Unpaired $T$-tests with Holm-Sidak correction (alpha $=0.017) .{ }^{\# \# \# ~} p<0.0001$ compared to IA2BC rats. 

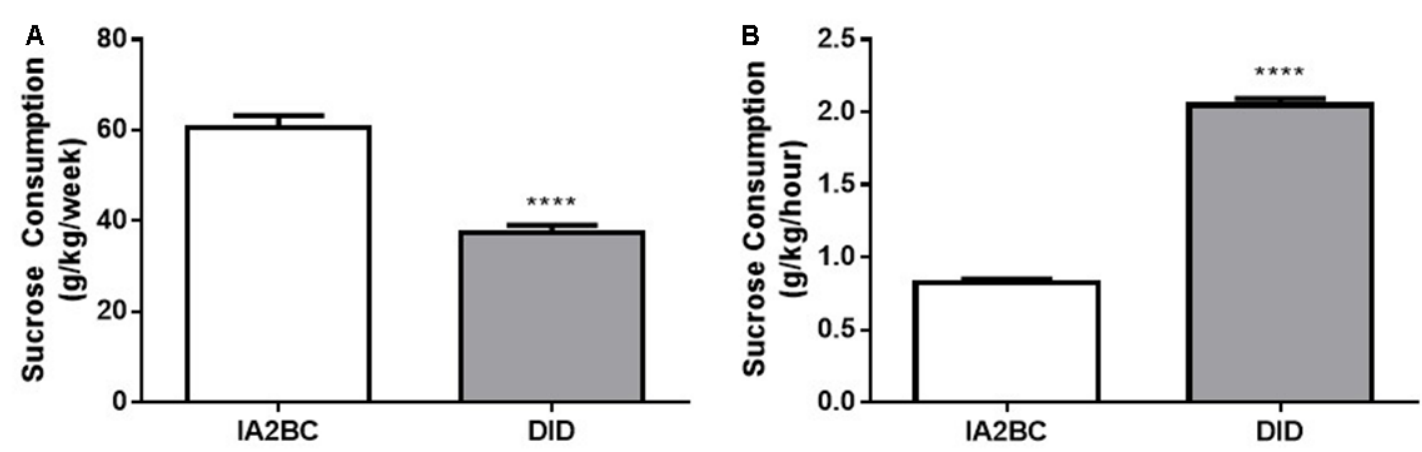

FIGURE 7 | Comparison of weekly and hourly sucrose consumption using the IA2BC and DID models. (A) Using the IA2BC model (white), rats consumed more $5 \%$ sucrose per week compared to rats using the DID model (gray). (B) However, the average hourly sucrose intake was greater for DID rats compared to IA2BC rats. $n=8-12$ per group. Unpaired two-tailed Student's $T$-test. ${ }^{* * * *} p<0.0001$.
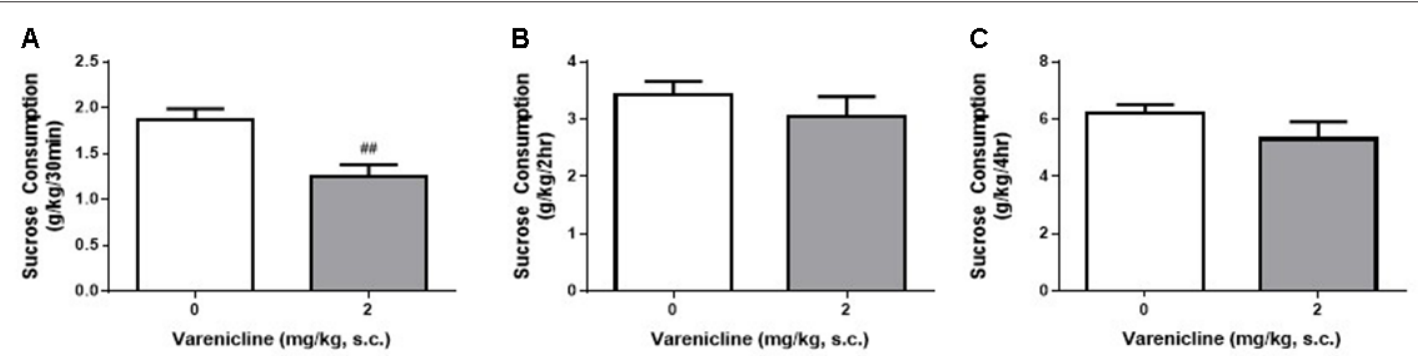

FIGURE 8 | Varenicline reduces sucrose consumption in DID rats following $\mathbf{3 0} \mathrm{min}$ of sucrose access. (A) Administration of $2 \mathrm{mg} / \mathrm{kg}$ varenicline (gray) produced a significant reduction in sucrose consumption compared to saline (white) following 30 min of sucrose access using the DID model. Varenicline had no effect on sucrose consumption at the $2 \mathrm{~h}$ (B) and $4 \mathrm{~h}$ (C) time points $n=8$ per group. Unpaired $T$-tests with Holm-Sidak correction (alpha $=0.017$ ).

$\# p<0.01$ compared to vehicle.

but not after $2 \mathrm{~h}$ (Figure 8B) or $4 \mathrm{~h}$ (Figure 8C) of sucrose access in DID rats (Unpaired T-test with Holm-Sidak correction, 30 min: $p=0.0050,2 \mathrm{~h}: p=0.4095$ and $4 \mathrm{~h}: p=0.1889$, $n=6)$.

\section{Comparison of Consumption between Models and Reinforcers}

To further explore the effect each model had on consumption of ethanol and sucrose, we compared ethanol to sucrose consumption produced by each model using multiple $t$-tests with Holm-Sidak correction (alpha $=0.010)$. We compared consumption after $30 \mathrm{~min}$ and $2 \mathrm{~h}$, as well as per session, weekly and hourly (Table 1). For both models, sucrose consumption was significantly greater than ethanol consumption $(p<0.0001)$ for all consumption parameters examined. Re-examination of each of these parameters for each reinforcer (see Table 1) with this statistical method produced similar results to those presented above. Ethanol consumption was greater per session for the IA2BC model $(p<0.001)$ but ethanol consumption per hour was greater with the DID model $(p<0.0001)$. Both models produced similar sucrose consumption after $30 \mathrm{~min}$ and $2 \mathrm{~h}$. While sucrose consumption was greater per session $(p<0.001)$ and per week $(p<0.0001)$ using the IA2BC model, like ethanol consumptions, hourly sucrose consumption was greater using the DID model $(p<0.0001)$.

\section{DISCUSSION}

In this study, we demonstrate for the first time that rats will consume moderate to high amounts of $20 \%$ ethanol and $5 \%$ sucrose using the DID model, a model traditionally used with mice. We compared their consumption to rats using the IA2BC model and found they produced different consumption patterns for ethanol and sucrose (see Table 1). While the IA2BC rats consumed more ethanol per session than DID rats, the DID rats displayed similar weekly consumption and higher initial and hourly consumption of ethanol. Together, this suggested that despite the IA2BC rats receiving $52 \mathrm{~h}$ more access to ethanol per week, the DID model produced greater binge-like consumption, particularly during the first $30 \mathrm{~min}$ of the drinking session. Similarly, The IA2BC rats consumed more sucrose per session and the DID rats displayed greater initial and hourly sucrose consumption. However, unlike ethanol, the IA2BC rats displayed greater weekly consumption of sucrose. Looking at ethanol and sucrose consumption across time during a standard drinking session for each model, DID rats consumed more ethanol than 
TABLE 1 | Comparison of ethanol and sucrose consumption for each model and reinforcer.

\begin{tabular}{|c|c|c|c|c|}
\hline \multirow[b]{2}{*}{ Consumption } & \multicolumn{2}{|c|}{ IA2BC } & \multicolumn{2}{|c|}{ DID } \\
\hline & Ethanol & Sucrose & Ethanol & Sucrose \\
\hline $\mathrm{g} / \mathrm{kg} / 30 \mathrm{~min}$ & $0.81 \pm 0.074$ & $1.98 \pm 0.085^{* * * *}$ & $0.73 \pm 0.077$ & $2.21 \pm 0.138^{\# \# \# \#}$ \\
\hline $\mathrm{g} / \mathrm{kg} / 2 \mathrm{~h}$ & $1.28 \pm 0.098$ & $3.58 \pm 0.198^{* * * *}$ & $1.23 \pm 0.093$ & $4.52 \pm 0.220^{\# \# \# \#}$ \\
\hline $\mathrm{g} / \mathrm{kg} / \mathrm{session}$ & $3.34 \pm 0.362$ & $19.85 \pm 0.881^{* * * *}$ & $1.83 \pm 0.140^{\$ \$}$ & $8.19 \pm 0.410^{\# \# \# \#, \& \& \&}$ \\
\hline g/kg/week & $10.56 \pm 1.163$ & $60.50 \pm 2.731^{* * * *}$ & $8.94 \pm 0.687$ & $37.30 \pm 1.727^{\# \# \# \#, \& \& \& \&}$ \\
\hline $\mathrm{g} / \mathrm{kg} / \mathrm{hour}$ & $0.14 \pm 0.007$ & $0.83 \pm 0.022^{* * * *}$ & $0.46 \pm 0.013^{\$ \$ \$ \$}$ & $2.05 \pm 0.045^{\# \# \# \#, \& \& \& \&}$ \\
\hline
\end{tabular}

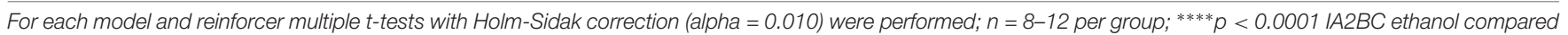
to IA2BC sucrose; \#\#\# $\quad$ \# 0.0001 DID ethanol compared to IA2BC Sucrose; $\$ \$ p<0.001, \$ \$ p<0.0001$ IA2BC ethanol compared to DID ethanol; \&\&\& $p<0.001$,

\&\&\&\& $p<0.0001$ IA2BC sucrose compared to DID sucrose.

IA2BC rats at $30 \mathrm{~min}$ but at $2 \mathrm{~h}$ their consumption was similar. For sucrose the DID rats consumed similar amounts of sucrose at $30 \mathrm{~min}$ and more sucrose at $2 \mathrm{~h}$. This may imply that the rate of sucrose consumption remains fairly consistent with time for both models, and while the DID model appears to induce greater binge-like sucrose consumption, the increased access time may be beneficial for studying the effects of long-term excessive sucrose consumption on the brain as it ensures exposure to greater amounts of sucrose. However, the data presented in this study indicate that the rate of ethanol consumption declines as access time increases and the rate of decline is more rapid for the DID compared to the IA2BC model. As such, the longer period of access to ethanol provided by the IA2BC model may not provide any additional benefits for studying binge-like consumption or the effects of long-term excessive ethanol consumption.

The differences in ethanol and sucrose consumption behaviors (discussed above) are, most likely, a reflection of the sedating effects of ethanol. Ethanol has both stimulatory and sedating effects depending on the dose administered. At low doses, ethanol increases locomotor activity, whereas higher doses reduce locomotor activity and can lead to loss of consciousness (June et al., 2003; Zapata et al., 2006; Kawakami et al., 2007; Arias et al., 2012; Kippin, 2014; Botia et al., 2015; Karlsson and Roman, 2016). As such, the more rapidly ethanol is consumed and the greater the intake, the more sedated the rat is likely to become, and the length of time the rat would be capable of engaging in the further consumption of ethanol would be reduced. Certainly, the elevated initial and hourly ethanol consumption of the DID model combined with its more rapid decline in ethanol consumption compared to the IA2BC model indicate not only a greater propensity to induce binge-like consumption but also a greater level of impairment. However, our 30 min BEC data do not support greater levels of impairment with the DID model compared to the IA2BC model and it may be that $30 \mathrm{~min}$ BEC measures is not suitable for use in rodents given their high metabolic rates (discussed further below). Other measures of motor impairment (for example, locomotor activity, rotarod, footprint analysis) are required to determine whether one model produces greater intoxication over the other. Sucrose exposure, on the other hand, does not appear to alter locomotor activity (Avena and Hoebel, 2003) and therefore, continued consumption of sucrose would not be expected to alter the ability to continue consumption. Measurements of locomotor activity during the drinking sessions are needed to confirm this, particularly as there is little data available regarding the effects of sucrose on locomotor activity. Another possibility is that the differences in consumption patterns observed result from differences in the types of neuronal pathways that ethanol and sucrose are capable of manipulating (for example, the reward pathway for ethanol [for review, see Söderpalm and Ericson, 2013) vs. the appetitive and reward pathways (Spangler et al., 2004) for sucrose], as well as differences in the amount of neurotransmitters released (Doyon et al., 2004; Funk and Dohrman, 2007) and the subtypes of receptors involved (Hodge et al., 1994). Unfortunately, many studies conducted which investigate these factors have compared sucrose consumption with sucrose-sweetened ethanol solutions (Hodge et al., 1994; Slawecki et al., 1997; Doherty and Gonzales, 2015) making it difficult to isolate the effects of ethanol alone. Future research is likely to address this now that voluntary $2 \mathrm{BC}$ models are available that do not require sucrose-fading to induce higher levels of ethanol consumption.

As a large proportion of the total ethanol consumed occurred during the initial period of the drinking session and the rate of ethanol consumed per hour for the DID model was higher than the IA2BC model (see Table 1), we examined the rat DID model to see if it could be defined as a model of human binge alcohol consumption. The first of the NIAAA defined criterion required the consumption of five or more standard drinks within $2 \mathrm{~h}$ (National Institute on Alcohol Abuse and Alcoholism (US) (2004)). We estimated that this was the equivalent of $0.87 \mathrm{~g} / \mathrm{kg}$ in $2 \mathrm{~h}$ for the average adult male. The ethanol consumption for the IA2BC and DID models easily exceeded this criterion, suggesting both procedures effectively model binge drinking. However, we were unable to achieve the second NIAAA criterion for binge drinking: BECs at or above $80 \mathrm{mg} / \mathrm{dL}$ (National Institute on Alcohol Abuse and Alcoholism (US) (2004)) after $30 \mathrm{~min}$ of access to ethanol. Previously, we reported that Wistar rats and alcohol preferring $(\mathrm{P})$ rats consuming $20 \%$ ethanol with the IA2BC model achieved BECs $4-93 \mathrm{mg} / \mathrm{dL}$ and $11-63 \mathrm{mg} / \mathrm{dL}$ (respectively) after $30 \mathrm{~min}$ of ethanol access (Simms et al., 2008). While approximately $30 \%$ of the Long Evans rats in the study achieved BECs above $90 \mathrm{mg} / \mathrm{dL}$, only one of the Wistar and none of the alcohol preferring $(\mathrm{P})$ rats achieved a $\mathrm{BEC}$ above $80 \mathrm{mg} / \mathrm{dL}$ using the IA2BC model (Simms et al., 2008). The range of the DID rats BECs $(14.24-54.00 \mathrm{mg} / \mathrm{dL})$ in this study 
was consistent with the previously reported BECs obtained using the IA2BC model. Based on this it seemed possible, regardless of the model used, 30 min may not be sufficient time for the rats to drink enough alcohol to achieve a BEC of $80 \mathrm{mg} / \mathrm{dL}$. However, data from other IA2BC studies using Wistar rats suggest that peak BECs occur by $30 \mathrm{~min}$ and increasing the length of ethanol access prior to $\mathrm{BEC}$ measurement does not increase the BEC obtained. Cippitelli et al. (2012) reported that Wistar rats consuming ethanol for $1 \mathrm{~h}$ had BECs ranging from $7 \mathrm{mg} / \mathrm{dL}$ to $61 \mathrm{mg} / \mathrm{dL}$ after consuming around $5.2 \mathrm{~g} / \mathrm{kg}$ of ethanol. Extending the ethanol access time to $2 \mathrm{~h}$ produced BECs of approximately $58 \mathrm{mg} / \mathrm{dL}$ following consumption of about $3.6 \mathrm{~g} / \mathrm{kg}$ of ethanol (George et al., 2012). A more likely possibility is that the higher metabolic rate and smaller body size of rats (compared to humans) makes it difficult for the rats to consume a sufficient amount of ethanol to reach the $80 \mathrm{mg} / \mathrm{dL}$ defined for humans in the NIAAA binge drinking criteria. Some studies with mice have utilized pyrazole, an alcohol dehydrogenase $(\mathrm{ADH})$ inhibitor, to prevent ethanol metabolism, and allow more consistent BEC measurement (Terdal and Crabbe, 1994; Griffin et al., 2009). Further studies are required to determine the time after ethanol access commences that peak BECs occur and to explore whether the use of pyrazole is required for rat BEC studies. Whether a BEC of $80 \mathrm{mg} / \mathrm{dL}$ or more is an appropriate measurement for classifying binge drinking in rodents also remains to be explored.

Finally, we assessed whether the rat DID model could be used to measure changes in ethanol and sucrose consumption following treatment with varenicline, a compound previously shown to reduce both ethanol and sucrose consumption using the IA2BC model in Wistar rats (Steensland et al., 2007; Shariff et al., 2016). Given the differences in the number of drinking sessions per week and ethanol and sucrose access times between the IA2BC and DID models, we chose to use varenicline at a dose of $2 \mathrm{mg} / \mathrm{kg}$ as we have previously shown this dose significantly reduced ethanol (Steensland et al., 2007) and sucrose (Shariff et al., 2016) consumption following two different lengths of exposure (4 and 12 weeks), whereas the lower dose of $1 \mathrm{mg} / \mathrm{kg}$ was only effective following 12 weeks of exposure to ethanol. Similar to previously demonstrated with the IA2BC model, varenicline reduced consumption at the $30 \mathrm{~min}$ and $2 \mathrm{~h}$ time points for ethanol and only at the $30 \mathrm{~min}$ time point for sucrose. However, we failed to demonstrate a significant effect at the $4 \mathrm{~h}$ time point for Varenicline on ethanol consumption, which we had shown with the IA2BC model (Steensland et al., 2007). Most likely this is due to differences in the statistical analysis as the previous study did not correct for multiple $t$-tests. In the present study, the $p$ value was less than 0.05 at $4 \mathrm{~h}$ and without the alpha value correction this could be considered significant. While there is the possibility that use of the alpha adjustment increases the amount of type II error, it is generally considered the more suitable statistical test as it reduces the amount of type I error when using multiple $t$-tests. Considering this, the level of significance achieved was also similar to that obtained with the IA2BC model for both ethanol and sucrose, indicating that the DID model may have similar sensitivity to the IA2BC model for screening novel compounds. Further testing with lower doses, additional time points and other compounds known to reduce ethanol and sucrose consumption is necessary to determine whether this is indeed the case or if one model of binge-like consumption offers greater sensitivity than the other, particularly for sucrose consumption. Although, the fact that we were able to detect a reduction in both sucrose and ethanol consumption with varenicline indicates that despite the reduced access time, the increased number of ethanol exposures and greater initial and hourly binge-like consumption produced by the DID model may be sufficient to produce signaling changes within the brain, similar to that reported with the IA2BC model (see Nielsen et al., 2012a; Klenowski et al., 2016). Further studies are also required to determine which aspects of the model (i.e., the increased number of consumption/withdrawal cycles of the DID model verses increased total amount consumed per session of the IA2BC model) are more important for modeling and producing binge-like consumption, if the DID model produces brain changes similar to those previously demonstrated with the IA2BC model for sucrose and ethanol consumption and whether these changes occur following fewer weeks of ethanol or sucrose exposure compared to the IA2BC model.

\section{CONCLUSION}

The DID model is adaptable for use as a rat model of both ethanol and sucrose binge-like consumption. It produces higher initial and hourly consumption of ethanol and sucrose compared to the IA2BC model, suggesting it induces greater binge-like consumption. Despite the lower total consumption per session produced by the DID model, it detected varenicline-induced reductions in both ethanol and sucrose consumption, similar to that reported for the IA2BC model. Further studies are required to dissect the importance of the number of exposures, length of access and total amount consumed for modeling consumption behaviors. However our data suggest that the DID model may offer advantages over the IA2BC model, particularly for studying binge-like consumption of ethanol. Further examination of the differences produced by each model is required to provide greater guidance for researchers when assessing the suitability of each model for their study.

\section{AUTHOR CONTRIBUTIONS}

JYH made substantial contributions to the conception and design of the work, the acquisition, analysis and interpretation of data for the work, drafting the work and revising it critically for important intellectual content. MS and EWHM made substantial contributions to the acquisition and analysis and revising the work critically for important intellectual content. SB made substantial contributions to the design of the work, interpretation of data for the work and revising the work critically for important intellectual content. All authors gave final approval of the version to be published and agreement to be accountable for all aspects of the work in ensuring that questions related to the accuracy or integrity of any part of the work are appropriately investigated and resolved. 


\section{FUNDING}

This work was supported by funding from the Australian Research Council (Grant No. FT1110884), the National Health and Medical Research Council (Grant No. 1049427) and the National Institute of Health (Grant No. NS59910).

\section{REFERENCES}

American Psychiatric Association. (2013). Diagnostic and Statistical Manual of Mental Disorders DSM-5. Arlington: American Psychiatric Association. Available online at: http://gateway.library.qut.edu.au/login?url=http://dsm. psychiatryonline.org/book.aspx?bookid $=556$

Arias, C., Revillo, D. A., and Spear, N. E. (2012). Chronic tolerance to the locomotor stimulating effect of ethanol in preweanling rats as a function of social stress. Alcohol 46, 245-252. doi: 10.1016/j.alcohol.2011.09.025

Augier, E., Flanigan, M., Dulman, R. S., Pincus, A., Schank, J. R., Rice, K. C., et al. (2014). Wistar rats acquire and maintain self-administration of $20 \%$; ethanol without water deprivation, saccharin/sucrose fading, or extended access training. Psychopharmacology (Berl) 231, 4561-4568. doi: 10.1007/s00213-0143605-3

Avena, N. M., and Hoebel, B. G. (2003). A diet promoting sugar dependency causes behavioral cross-sensitization to a low dose of amphetamine. Neuroscience 122, 17-20. doi: 10.1016/s0306-4522(03)00502-5

Avena, N. M., Rada, P., and Hoebel, B. G. (2008). Evidence for sugar addiction: behavioral and neurochemical effects of intermittent, excessive sugar intake. Neurosci. Biobehav. Rev. 32, 20-39. doi: 10.1016/j.neubiorev.2007.04.019

Benton, D. (2010). The plausibility of sugar addiction and its role in obesity and eating disorders. Clin. Nutr. 29, 288-303. doi: 10.1016/j.clnu.2009. 12.001

Bito-Onon, J. J., Simms, J. A., Chatterjee, S., Holgate, J., and Bartlett, S. E. (2011). Varenicline, a partial agonist at neuronal nicotinic acetylcholine receptors, reduces nicotine-induced increases in 20\%; ethanol operant self-administration in Sprague-Dawley rats. Addict. Biol. 16, 440-449. doi: 10.1111/j.1369-1600. 2010.00309.x

Bonomo, Y. A., Bowes, G., Coffey, C., Carlin, J. B., and Patton, G. C. (2004). Teenage drinking and the onset of alcohol dependence: a cohort study over seven years. Addiction 99, 1520-1528. doi: 10.1111/j.1360-0443.2004.00846.x

Botia, B., Legastelois, R., Houchi, H., and Naassila, M. (2015). Basal anxiety negatively correlates with vulnerability to ethanol-induced behavioral sensitization in DBA/2J mice: modulation by diazepam. Alcohol. Clin. Exp. Res. 39, 45-54. doi: 10.1111/acer.12595

Carnicella, S., Ron, D., and Barak, S. (2014). Intermittent ethanol access schedule in rats as a preclinical model of alcohol abuse. Alcohol 48, 243-252. doi: 10.1016/j.alcohol.2014.01.006

CDC. (2016). CDC/alcohol and public health/frequently asked questions. Available online at: http://www.cdc.gov/alcohol/faqs.htm. Accessed August 23, 2016.

Cippitelli, A., Damadzic, R., Singley, E., Thorsell, A., Ciccocioppo, R., Eskay, R. L., et al. (2012). Pharmacological blockade of corticotropin-releasing hormone receptor 1 (CRH1R) reduces voluntary consumption of high alcohol concentrations in non-dependent Wistar rats. Pharmacol. Biochem. Behav. 100, 522-529. doi: 10.1016/j.pbb.2011.10.016

Clapper, R. L., and Lipsitt, L. P. (1992). Young heavy drinkers and their drinking experiences: predictors of later alcohol use. Int. J. Addict. 27, 1211-1221. doi: 10.3109/10826089209047345

Coe, J. W., Brooks, P. R., Vetelino, M. G., Wirtz, M. C., Arnold, E. P., Huang, J., et al. (2005). Varenicline: an $\alpha 4 \beta 2$ nicotinic receptor partial agonist for smoking cessation. J. Med. Chem. 48, 3474-3477. doi: 10.1021/jm050069n

Doherty, J. M., and Gonzales, R. A. (2015). Lack of effect of nucleus accumbens dopamine D1 receptor blockade on consumption during the first two days of operant self-administration of sweetened ethanol in adult Long-Evans rats. Alcohol 49, 543-551. doi: 10.1016/j.alcohol.2015.05.003

Doyon, W. M., Ramachandra, V., Samson, H. H., Czachowski, C. L., and Gonzales, R. A. (2004). Accumbal dopamine concentration during operant self-administration of a sucrose or a novel sucrose with ethanol solution. Alcohol 34, 261-271. doi: 10.1016/j.alcohol.2004.10.004

\section{ACKNOWLEDGMENTS}

We wish to thank Mr. Omkar Patkar and Dr. Michael Morgan for their technical assistance during the behavioral experiments and Dr. Paul Klenowski and Dr. Arnauld Belmer for their editorial advice.

Feduccia, A. A., Simms, J. A., Mill, D., Yi, H. Y., and Bartlett, S. E. (2014). Varenicline decreases ethanol intake and increases dopamine release via neuronal nicotinic acetylcholine receptors in the nucleus accumbens. Br. J. Pharmacol. 171, 3420-3431. doi: 10.1111/bph.12690

Funk, C. K., and Dohrman, D. P. (2007). Chronic ethanol exposure inhibits dopamine release via effects on the presynaptic actin cytoskeleton in PC12 cells. Brain Res. 1185, 86-94. doi: 10.1016/j.brainres.2007.09.069

Galic, M. A., and Persinger, M. A. (2002). Voluminous sucrose consumption in female rats: increased "nippiness" during periods of sucrose removal and possible oestrus periodicity. Psychol. Rep. 90, 58-60. doi: 10.2466/pr0.90.1. 58-60

George, O., Sanders, C., Freiling, J., Grigoryan, E., Vu, S., Allen, C. D., et al. (2012). Recruitment of medial prefrontal cortex neurons during alcohol withdrawal predicts cognitive impairment and excessive alcohol drinking. Proc. Natl. Acad. Sci. U S A 109, 18156-18161. doi: 10.1073/pnas.11165 23109

Griffin, W. C. III. (2014). Alcohol dependence and free-choice drinking in mice. Alcohol 48, 287-293. doi: 10.1016/j.alcohol.2013.11.006

Griffin, W. C. III., Lopez, M. F., and Becker, H. C. (2009). Intensity and duration of chronic ethanol exposure is critical for subsequent escalation of voluntary ethanol drinking in mice. Alcohol. Clin. Exp. Res. 33, 1893-1900. doi: 10.1111/j. 1530-0277.2009.01027.x

Hodge, C. W., Samson, H. H., Tolliver, G. A., and Haraguchi, M. (1994). Effects of intraaccumbens injections of dopamine agonists and antagonists on sucrose and sucrose-ethanol reinforced responding. Pharmacol. Biochem. Behav. 48, 141-150. doi: 10.1016/0091-3057(94)90510-x

Hopf, F. W., and Lesscher, H. M. B. (2014). Rodent models for compulsive alcohol intake. Alcohol 48, 253-264. doi: 10.1016/j.alcohol.2014.03.001

June, H. L., Foster, K. L., McKay, P. F., Seyoum, R., Woods, J. E. II., Harvey, S. C., et al. (2003). The reinforcing properties of alcohol are mediated by $\mathrm{GABA}_{\mathrm{A} 1}$ receptors in the ventral pallidum. Neuropsychopharmacology 28, 2124-2137. doi: 10.1038/sj.npp.1300239

Karlsson, O., and Roman, E. (2016). Dose-dependent effects of alcohol administration on behavioral profiles in the MCSF test. Alcohol 50, 51-56. doi: 10.1016/j.alcohol.2015.10.003

Kawakami, S. E., Quadros, I. M., Takahashi, S., and Suchecki, D. (2007). Long maternal separation accelerates behavioural sensitization to ethanol in female but not in male mice. Behav. Brain Res. 184, 109-116. doi: 10.1016/j.bbr.2007. 06.023

Kippin, T. E. (2014). Adaptations underlying the development of excessive alcohol intake in selectively bred mice. Alcohol. Clin. Exp. Res. 38, 36-39. doi: 10.1111/acer.12327

Klenowski, P. M., Shariff, M. R., Belmer, A., Fogarty, M. J., Mu, E. W., Bellingham, M. C., et al. (2016). Prolonged consumption of sucrose in a binge-like manner, alters the morphology of medium spiny neurons in the nucleus accumbens shell. Front. Behav. Neurosci. 10:54. doi: 10.3389/fnbeh. 2016.00054

Lemon, C. H., Brasser, S. M., and Smith, D. V. (2004). Alcohol activates a sucrose-responsive gustatory neural pathway. J. Neurophysiol. 92, 536-544. doi: 10.1152/jn.00097.2004

Lenoir, M., Serre, F., Cantin, L., and Ahmed, S. H. (2007). Intense sweetness surpasses cocaine reward. PLoS One 2:e698. doi: 10.1371/journal.pone. 0000698

Lhuintre, J. P., Moore, N., Tran, G., Steru, L., Langrenon, S., Daoust, M., et al. (1990). Acamprosate appears to decrease alcohol intake in weaned alcoholics. Alcohol Alcohol. 25, 613-622. doi: 10.1093/oxfordjournals.alcalc. a045057

Mangabeira, V., Garcia-Mijares, M., and Silva, M. T. (2015). Sugar withdrawal and differential reinforcement of low rate (DRL) performance in rats. Physiol. Behav. 139, 468-473. doi: 10.1016/j.physbeh.2014.09.017 
McBride, W. J., and Li, T. K. (1998). Animal models of alcoholism: neurobiology of high alcohol-drinking behavior in rodents. Crit. Rev. Neurobiol. 12, 339-369. doi: 10.1615/critrevneurobiol.v12.i4.40

Mill, D. J., Bito-Onon, J. J., Simms, J. A., Li, R., and Bartlett, S. E. (2013). Fischer rats consume $20 \%$ ethanol in a long-term intermittent-access two-bottle-choice paradigm. PLoS One 8:e79824. doi: 10.1371/journal.pone.0079824

Mitchell, J. M., Teague, C. H., Kayser, A. S., Bartlett, S. E., and Fields, H. L. (2012). Varenicline decreases alcohol consumption in heavy-drinking smokers. Psychopharmacology (Berl) 223, 299-306. doi: 10.1007/s00213-0122717-x

National Institute on Alcohol Abuse and Alcoholism (US), National Institutes Of Health (US) and Services, and U. D. O. H. A. H. (2004). NIAAA council approves definition of binge drinking. NIAAA Newsl. 3.

Nielsen, C. K., Simms, J. A., Bito-Onon, J. J., Li, R., Ananthan, S., and Bartlett, S. E. (2012a). The delta opioid receptor antagonist, SoRI-9409, decreases yohimbine stress-induced reinstatement of ethanol-seeking. Addict. Biol. 17, 224-234. doi: 10.1111/j.1369-1600.2010.00295.x

Nielsen, C. K., Simms, J. A., Li, R., Mill, D., Yi, H., Feduccia, A. A., et al. (2012b). Delta-opioid receptor function in the dorsal striatum plays a role in high levels of ethanol consumption in rats. J. Neurosci. 32, 4540-4552. doi: 10.1523/JNEUROSCI.5345-11.2012

Nielsen, C. K., Simms, J. A., Pierson, H. B., Li, R., Saini, S. K., Ananthan, S., et al. (2008). A novel delta opioid receptor antagonist, SoRI-9409, produces a selective and long-lasting decrease in ethanol consumption in heavydrinking rats. Biol. Psychiatry 64, 974-981. doi: 10.1016/j.biopsych.2008. 07.018

Patkar, O. L., Belmer, A., Holgate, J. Y., Tarren, J. R., Shariff, M. R., Morgan, M., et al. (2016). The antihypertensive drug pindolol attenuates long-term but not short-term binge-like ethanol consumption in mice. Addict. Biol. doi: 10.1111/adb.12359 [Epub ahead of print].

Rhodes, J. S., Best, K., Belknap, J. K., Finn, D. A., and Crabbe, J. C. (2005). Evaluation of a simple model of ethanol drinking to intoxication in C57BL/6J mice. Physiol. Behav. 84, 53-63. doi: 10.1016/j.physbeh.2004. 10.007

Santos, N., Chatterjee, S., Henry, A., Holgate, J., and Bartlett, S. E. (2013). The $\alpha 5$ neuronal nicotinic acetylcholine receptor subunit plays an important role in the sedative effects of ethanol but does not modulate consumption in mice. Alcohol. Clin. Exp. Res. 37, 655-662. doi: 10.1111/acer.12009

Shariff, M., Quik, M., Holgate, J., Morgan, M., Patkar, O. L., Tam, V., et al. (2016). Neuronal nicotinic acetylcholine receptor modulators reduce sugar intake. PLoS One 11:e0150270. doi: 10.1371/journal.pone.0150270

Simms, J. A., Bito-Onon, J. J., Chatterjee, S., and Bartlett, S. E. (2010). Long-Evans rats acquire operant self-administration of $20 \%$ ethanol without sucrose fading. Neuropsychopharmacology 35, 1453-1463. doi: 10.1038/npp. 2010.15

Simms, J. A., Haass-Koffler, C. L., Bito-Onon, J., Li, R., and Bartlett, S. E. (2012). Mifepristone in the central nucleus of the amygdala reduces yohimbine stress-induced reinstatement of ethanol-seeking. Neuropsychopharmacology 37, 906-918. doi: 10.1038/npp.2011.268

Simms, J. A., Nielsen, C. K., Li, R., and Bartlett, S. E. (2014). Intermittent access ethanol consumption dysregulates CRF function in the hypothalamus and is attenuated by the CRF-R1 antagonist, CP-376395. Addict. Biol. 19, 606-611. doi: $10.1111 / \mathrm{adb} .12024$

Simms, J. A., Richards, J. K., Mill, D., Kanholm, I., Holgate, J. Y., and Bartlett, S. E. (2011). Induction of multiple reinstatements of ethanol- and sucrose-seeking behavior in Long-Evans rats by the $\alpha-2$ adrenoreceptor antagonist yohimbine. Psychopharmacology (Berl) 218, 101-110. doi: 10.1007/s00213-011-2451-9

Simms, J. A., Steensland, P., Medina, B., Abernathy, K. E., Chandler, L. J., Wise, R., et al. (2008). Intermittent access to $20 \%$ ethanol induces high ethanol consumption in Long-Evans and Wistar rats. Alcohol. Clin. Exp. Res. 32, 1816-1823. doi: 10.1111/j.1530-0277.2008.00753.x

Slawecki, C. J., Hodge, C. W., and Samson, H. H. (1997). Dopaminergic and opiate agonists and antagonists differentially decrease multiple schedule responding maintained by sucrose/ethanol and sucrose. Alcohol 14, 281-294. doi: 10.1016/s0741-8329(96)00153-x

Söderpalm, B., and Ericson, M. (2013). Neurocircuitry involved in the development of alcohol addiction: the dopamine system and its access points. Curr. Top. Behav. Neurosci. 13, 127-161. doi: 10.1007/7854_2011_170

Spangler, R., Wittkowski, K. M., Goddard, N. L., Avena, N. M., Hoebel, B. G., and Leibowitz, S. F. (2004). Opiate-like effects of sugar on gene expression in reward areas of the rat brain. Mol. Brain Res. 124, 134-142. doi: 10.1016/j.molbrainres. 2004.02.013

Srinivasan, S., Simms, J. A., Nielsen, C. K., Lieske, S. P., Bito-Onon, J. J., Yi, H., et al. (2012). The dual orexin/hypocretin receptor antagonist, almorexant, in the ventral tegmental area attenuates ethanol self-administration. PLoS One 7:e44726. doi: 10.1371/journal.pone.0044726

Srisontiyakul, J., Kastman, H. E., Krstew, E. V., Govitrapong, P., and Lawrence, A. J. (2016). The nicotinic $\alpha 6$-subunit selective antagonist bPiDI reduces alcohol self-administration in alcohol-preferring rats. Neurochem. Res. 41, 3206-3214. doi: 10.1007/s11064-016-2045-3

Steensland, P., Simms, J. A., Holgate, J., Richards, J. K., and Bartlett, S. E. (2007). Varenicline, an $\alpha 4 \beta 2$ nicotinic acetylcholine receptor partial agonist, selectively decreases ethanol consumption and seeking. Proc. Natl. Acad. Sci. U S A 104, 12518-12523. doi: 10.1073/pnas.0705368104

Steensland, P., Simms, J. A., Nielsen, C. K., Holgate, J., Bito-Onon, J. J., and Bartlett, S. E. (2010). The neurokinin 1 receptor antagonist, ezlopitant, reduces appetitive responding for sucrose and ethanol. PLoS One 5:e12527. doi: 10.1371/journal.pone.0012527

Terdal, E. S., and Crabbe, J. C. (1994). Indexing withdrawal in mice: matching genotypes for exposure in studies using ethanol vapor inhalation. Alcohol. Clin. Exp. Res. 18, 542-547. doi: 10.1111/j.1530-0277.1994.tb 00907.x

Vengeliene, V., Bilbao, A., and Spanagel, R. (2014). The alcohol deprivation effect model for studying relapse behavior: a comparison between rats and mice. Alcohol 48, 313-320. doi: 10.1016/j.alcohol.2014.03.002

Vetter, C. S., Doremus-Fitzwater, T. L., and Spear, L. P. (2007). Time course of elevated ethanol intake in adolescent relative to adult rats under continuous, voluntary-access conditions. Alcohol. Clin. Exp. Res. 31, 1159-1168. doi: 10.1111/j.1530-0277.2007.00417.x

Walpole, S. C., Prieto-Merino, D., Edwards, P., Cleland, J., Stevens, G., and Roberts, I. (2012). The weight of nations: an estimation of adult human biomass. BMC Public Health 12:439. doi: 10.1186/1471-2458-12-439

Wells, J. E., Horwood, L. J., and Fergusson, D. M. (2004). Drinking patterns in mid-adolescence and psychosocial outcomes in late adolescence and early adulthood. Addiction 99, 1529-1541. doi: 10.1111/j.1360-0443.2004.00918.x

WHO. (2014). Global Status Report on Noncommunicable Diseases 2014. World Health Organization. Available online at: http://qut.eblib.com.au/patron/ FullRecord.aspx?p=2059287

Wise, R. A. (1973). Voluntary ethanol intake in rats following exposure to ethanol on various schedules. Psychopharmacologia 29, 203-210. doi: 10.1007/bf00414034

Zapata, A., Gonzales, R. A., and Shippenberg, T. S. (2006). Repeated ethanol intoxication induces behavioral sensitization in the absence of a sensitized accumbens dopamine response in C57BL/6J and DBA/2J mice. Neuropsychopharmacology 31, 396-405. doi: 10.1038/sj.npp.1300833

Conflict of Interest Statement: The authors declare that the research was conducted in the absence of any commercial or financial relationships that could be construed as a potential conflict of interest.

Copyright (c) 2017 Holgate, Shariff, Mu and Bartlett. This is an open-access article distributed under the terms of the Creative Commons Attribution License (CC BY). The use, distribution and reproduction in other forums is permitted, provided the original author(s) or licensor are credited and that the original publication in this journal is cited, in accordance with accepted academic practice. No use, distribution or reproduction is permitted which does not comply with these terms. 